\title{
LA TRANSMISIÓN IMPRESA DEL TEATRO DE ROJAS ZORRILLA*
}

\author{
RAFAEL GONZÁLEZ CAÑAL \\ Universidad de Castilla-La Mancha
}

Uno de los problemas más significativos con el que nos encontramos al acercarnos al teatro de Francisco de Rojas Zorrilla (1607-1648) es la falta de textos fiables, así como la persistencia de problemas de atribución y autoría en algunas de sus obras. No contamos con un corpus dramático depurado de este autor. Algo parecido ocurre con muchos de los dramaturgos de nuestro Siglo de Oro.

Todavía en la actualidad, sólo las obras más conocidas de Rojas tienen ediciones críticas y anotadas solventes: Entre bobos anda el juego, por ejemplo, ha merecido el aprecio de la crítica y ha sido editada por Maria Grazia Profeti en dos ocasiones (Madrid, Anaya, 1984 y Barcelona, Crítica, 1998) y por Ana Suárez Miramón (Barcelona, Planeta, 1990); también Del rey abajo ninguno, cuya autoría sigue siendo discutida, ha sido editada en las colecciones de clásicos más importantes por reconocidos especialistas: Jean Testas (Madrid, Castalia, 1971), Brigitte Wittman (Madrid, Cátedra, 1980) y Ana Suárez Miramón (Barcelona, Planeta, 1990). Recientemente ha aparecido una edición de otras dos obras esenciales del autor toledano: Donde hay agravios no hay celos y Abrir el ojo. ${ }^{1}$

\footnotetext{
* Este trabajo se inscribe en el proyecto de investigación titulado Edición de la obra dramática de Rojas Zorrilla. I (HUM2005-07408-C04-01/FILO), financiado por el Ministerio de Educación y Ciencia.
} 
Fuera de estas cuatro obras, sólo existen algunas ediciones ocasionales entre las que destacan las llevadas a cabo por el investigador norteamericano Raymond R. MacCurdy, que es indudablemente el mayor especialista en la obra dramática de Rojas: Morir pensando matar y La vida en el ataúd (1961), Lucrecia y Tarquino (1963), Numancia cercada y Numancia destruida (1977), etc. ${ }^{2}$

Para el resto de las obras de Rojas hay que acudir todavía a la edición realizada por Ramón de Mesonero Romanos en 1861 en la Biblioteca de Autores Españoles, reeditada en diferentes ocasiones (la última en 1952).

Por otra parte, el corpus dramático rojiano es bastante más amplio de las 30 obras que publicó en su día Mesonero. En total, contabilizamos hoy 44 obras de autoría segura más otras 13 piezas escritas en colaboración con otros autores, es decir, un total de 57 obras que con toda certeza le pertenecen. Hay unos diez textos más que presentan problemas de atribución y autoría que hay que dilucidar, entre ellos el que le ha dado fama universal: Del rey abajo ninguno. También cuenta Rojas con siete autos sacramentales y dos entremeses. A pesar de su temprana desaparición, el número de obras que escribió y que se le atribuyen es elevado. ${ }^{3}$

Pues bien, para leer y analizar estas obras de Rojas no incluidas en el volumen de Mesonero Romanos, es necesario acudir todavía a ediciones y testimonios del siglo XVII, muchas veces mutilados y deturpados. Hay obras que se conservan en un único manuscrito (El primer marqués de Astorga, El mejor amigo el muerto y capuchino escocés, Santa Táez, etc.) o en un único testimonio impreso (No intente el que no es dichoso, Los encantos de la China, El médico de su amor, Más vale maña que fuerza, etc.), mientras que otras, que no coinciden con las más conocidas hoy, tuvieron una transmisión impresa muy notoria a partir de las llamadas comedias sueltas, testimonio indudable del éxito de una comedia en los siglos XVII y XVIII. Es curioso constatar cómo algunas de las comedias de Rojas hoy completamente olvidadas tuvieron que tener cierta difusión en dicho periodo, a juzgar por el número de testimonios conservados: tal es el caso de

\footnotetext{
1 Donde hay agravios no hay celos y Abrir el ojo, ed. F. B. Pedraza Jiménez y M. Rodríguez Cáceres, Madrid, Castalia, 2005.

2 Morir pensando matar y La vida en el ataúd, ed. R. R. MacCurdy, Madrid, Espasa-Calpe, 1961 (Clásicos Castellanos, $\mathrm{n}^{\mathrm{o}}$ 153); Lucrecia y Tarquino, ed. R. R. MacCurdy, Alburquerque/New Mexico, Universidad de New Mexico Press, 1963; y Numancia cercada y Numancia destruida, ed. R. R. MacCurdy, Madrid, José Porrúa Turanzas, 1977.

3 Vid. R. González Cañal, «Incógnitas y hallazgos en el repertorio dramático de Rojas Zorrilla», en Actas del Congreso Internacional Los segundones. Importancia y valor de su presencia en el teatro aurisecular, organizado por la Università degli Studi di Milano y el GRISO (Universidad de Navarra), celebrado en Gargnano di Garda (Italia), del 18 al 21 de septiembre de 2005, en prensa.
} 
Casarse por vengarse, Los áspides de Cleopatra, No hay amigo para amigo, El desafío de Carlos V, Progne y Filomena o Primero es la honra que el gusto.

La intensa actividad escénica del siglo XVII provocó una circulación enorme de manuscritos entre escritores, copistas y comediantes. Pero esta gran acogida que obtuvo el teatro no se limitó exclusivamente a los escenarios, como parece lógico por su género, sino que pronto se manifestó también en la lectura, lo que impulsó una rica transmisión impresa del género, a la vez que propició un fructífero negocio para imprentas y librerías.

La carrera dramática de Rojas Zorrilla fue breve en el tiempo pero de gran intensidad. Su periodo más fecundo se sitúa en los años treinta del siglo XVII, etapa en la que coincidieron en plena actividad representantes de las tres grandes generaciones de la dramaturgia barroca. Rojas ocupó en esos años un puesto relevante en el escalafón dramático, llegando a ser uno de los dramaturgos preferidos de la corte, en competición con Calderón, e incluso por encima de él en los primeros momentos. Por ello no es de extrañar la adscripción a su nombre de obras de otros autores menos populares en aquellos años y de menor atractivo para los profesionales de la escena y, sobre todo, para el público lector.

La primera mención al escritor toledano se encuentra en el «Índice de los ingenios de Madrid» del Para todos (1632), de Juan Pérez de Montalbán: «Don Francisco de Roxas, poeta florido y galante, como dicen los aplausos de las ingeniosas comedias que tiene escritas.»4 Además, atestigua su popularidad el hecho de que participe con un soneto en el libro titulado Anfiteatro de Felipe el Grande que publicó José de Pellicer de Tovar en $1631^{5}$ o que contribuya con poemas breves a algunas publicaciones colectivas de la época. ${ }^{6}$

La primera representación constatada de una pieza suya corresponde a Persiles y Segismunda, fechada el 23 de febrero de 1633, que tuvo lugar en el palacio del Pardo, lo que ya marca un aspecto destacado de su labor: la consideración y aprecio de la corte. No es extraño que años después fuera una

\footnotetext{
4 Para todos, exemplos morales, homanos y divinos... Madrid, Imprenta del Reyno, a costa de Alonso Pérez, 1632, f. 345v.

${ }^{5}$ Anfiteatro de Felipe el Grande... Que contiene los elogios que han celebrado la suerte que hizo en el toro en la fiesta agonal del 13 de Octubre deste año de 1631. Dedícale á Su majestad D. José Pellicer de Tovar... Madrid: Iuan Gonçález, [1631], Epigrama LXI, f. 43r.

6 Por ejemplo: el romance "Agora que el coraçón / con las alas que le informan...», en Avisos para la mverte escritos por algunos ingenios de España... recogidos y pvblicados por don Luis Remírez de Arellano, Madrid, Viuda de Alonso Martín, a costa de Alonso Pérez, 1634, f. 66r-68r; o el soneto «Este que en decoroso monumento,...», en Fama pósthuma a la vida y muerte del Doctor Frey Lope Félix de Vega Carpio... por el Doctor Ivan Pérez de Montalván, Madrid, Imprenta de Reyno, 1636, f. $50 \mathrm{v}$.
} 
obra suya, Los bandos de Verona, la elegida para inaugurar el Coliseo del Buen Retiro en 1640, al cierre de la década principal de su fulgurante carrera.

$\mathrm{Su}$ actividad teatral en la corte arrecia en los años centrales de esa década, 1635-1636, en consonancia con su irrupción en las imprentas y librerías. Está constatada la exhibición de al menos una docena de piezas, entre las escritas solo por él (Peligrar en los remedios, No hay ser padre siendo rey, El desafío de Carlos V, El profeta falso Mahoma, Santa Isabel, reina de Portugal, Progne y Filomena, Obligados y ofendidos y No hay amigo para amigo) y las colaboradas (El catalán Serrallonga, con Luis Vélez de Guevara y Antonio Coello; El jardín de Falerina, con Calderón y Coello; El mejor amigo el muerto, con Belmonte y Calderón; El villano gran señor y gran Tamorlán de Persia, con Villanueva y Roa). Al año siguiente se registran representaciones cortesanas de otras tres obras: Donde hay agravios no hay celos, El más impropio verdugo y El robo de las sabinas (en colaboración con Juan y Antonio Coello). Estas noticias se completan con otras sobre su participación en academias y certámenes. ${ }^{7}$ En 1640, el año de inauguración del Coliseo, aparecía en las librerías la Primera parte de sus comedias. ${ }^{8}$ El éxito de Rojas como dramaturgo quedaba así refrendado y se abría un nuevo cauce para su difusión: la transmisión impresa.

Las referencias escénicas son más escasas en el siguiente decenio, años adversos para el teatro a causa de la muerte de Isabel de Borbón en octubre de 1644, que trajo consigo la suspensión de las representaciones, renovada después por la del príncipe Baltasar Carlos en octubre de 1646. Con los teatros cerrados, aún cobraba más interés la posibilidad de difundir las obras dramáticas a través de la imprenta. En 1645 vio la luz la Segunda parte de sus comedias. ${ }^{9}$ No llegó a salir la tercera, que al parecer preparaba,10 ya que el 23 de enero de 1648, a los cuarenta años de edad, moría repentinamente.

Rojas no perdió popularidad tras su muerte y su teatro continuó presente en los escenarios y en las imprentas hasta principios del siglo XIX. Eso sí, el tiempo fue ejerciendo una selección en su repertorio dramático, según

\footnotetext{
7 Rojas intervino activamente en las academias celebradas en el Buen Retiro en 1637 y 1638 ; vid. Academia burlesca que se hizo en Buen Retiro a la majestad de Filipo Cuarto el Grande. Año de 1637, edición crítica, prólogo y notas de María Teresa Julio, Madrid-Frankfurt, Iberoamericana-Vervuert, 2007.

8 Primera parte de las comedias de Don Francisco de Rojas de Zorrilla, Madrid, María de Quiñones. A costa de Pedro Coello, Mercader de libros, 1640.

9 Segunda parte de las comedias de Don Francisco de Rojas Zorrilla, Madrid, Francisco Martínez. A costa de Pedro Coello, Mercader de libros, 1645.

10 «Cabales te las confío, si acaso eres maldiciente, materia te doy para murmurar, huélgate que tu dinero te cuesta; y, si eres bien intencionado, yo te haré pagar la merced que hicieres a mi Segunda Parte con dar a la estampa la tercera. Dios te guarde.» (Segunda parte de las comedias..., Madrid, Francisco Martínez, 1645).
} 
criterios que hay que estudiar con detalle, tanto en el canal escénico como en el libresco. Los datos sobre representaciones en el siglo XVIII en los teatros de Madrid, según la cartelera de Andioc y Coulon, muestran la presencia que tuvieron algunos títulos de Rojas como, sobre todo, Donde hay agravios no hay celos (programada 118 veces), pero también otras obras suyas o en colaboración con otros autores: El monstruo de la fortuna (85), La más hidalga hermosura (48), Los áspides de Cleopatra (47), Del rey abajo ninguno (44), Entre bobos anda el juego (44), El catalán Serrallonga (40), Los bandos de Verona (35), etc. ${ }^{11}$

El eco de la obra de Rojas Zorrilla también traspasó las fronteras. Hay que recordar en especial la deuda que con algunas de sus obras contrajeron dramaturgos franceses como Thomas Corneille, Paul Scarron, Jean Rotrou o Alain-René Lesage. ${ }^{12}$

\section{ROJAS EN LA IMPRENTA DEL SIGLO XVII}

El número de piezas atribuidas o atribuibles al escritor ha variado en las sucesivas listas y recuentos de los especialistas. Son arduos los problemas que surgen para localizar algunas de las que aparecen mencionadas en las diferentes listas. Tampoco es fácil determinar en muchas ocasiones la autenticidad de algunas obras. Al menos, ofrecen plena garantía las 24 comedias que aparecieron en las dos partes publicadas por él en 1640 y 1645, entre las cuales hay una, Los tres blasones de España, que fue escrita en colaboración con Antonio Coello.

En 1735 los herederos de Medel del Castillo listaron a nombre de Rojas 81 títulos de comedias en exclusiva (es decir, sin contar las de colaboración) y 10 de autos sacramentales. Emilio Cotarelo (1911) menciona 44 obras auténticas propias, 13 en colaboración, 21 apócrifas y dudosas, y 11 desconocidas. Por su parte, Raymond R. MacCurdy (1965) consigna 37 comedias propias, 31 apócrifas

11 R. Andioc y M. Coulon, Cartelera teatral madrileña del siglo XVIII (1708-1808), Toulouse, Presses Universitaires du Mirail, 1996, 2 vols. Los datos que nos aporta Juliá correspondientes a la cartelera valenciana son similares: Donde hay agravios no hay celos (17), Los áspides de Cleopatra (19), El catalán Serrallonga (17), El mosntruo de la fortuna (14), etc. (E. Juliá, «Preferencias teatrales del público valenciano en el siglo XVIII», RFE, 20 (1933), pp. 113-159). Sobre la recepción del teatro de Rojas en el siglo XVIII, vid. los trabajos de E. Palacios Fernández, «Pervivencias del teatro barroco. Recepción de Rojas Zorrilla en el siglo XVIII» y M. E. Arenas Cruz, «Las representaciones de Rojas en el siglo XVIII y su valoración en el Memorial literario», en F. B. Pedraza Jiménez, R. González Cañal y E. Marcello (eds.), Francisco de Rojas Zorrilla, poeta dramático. Actas de las XXII Jornadas de teatro clásico, Almagro 13, 14 y 15 de julio de 1999, Almagro (Ciudad Real), Universidad de CastillaLa Mancha-Festival de Almagro, 2000, pp. 349-378 y pp. 379-394 respectivamente.

12 Vid. C. Couderc, «Recepción y adaptación de Rojas Zorrilla en Francia (siglo XVII): algunos ejemplos», en F. B. Pedraza Jiménez, R. González Cañal y E. Marcello (eds.), Francisco de Rojas Zorrilla, poeta dramático..., op. cit., pp. 323-348. 
o dudosas, 7 perdidas, 15 en colaboración, 8 autos sacramentales propios y 8 apócrifos, y dos entremeses. ${ }^{13}$

No hay que olvidar que la notoriedad adquirida por Rojas hizo que una y otra vez los impresores de la segunda mitad del siglo XVII y los del siglo siguiente dieran preferencia a su nombre como reclamo a la hora de imprimir y vender comedias. Ya el propio dramaturgo se quejaba amargamente en la dedicatoria al lector de la Segunda parte de las comedias... (Madrid, Francisco Martínez, 1645) de la falta de rigor de impresores y libreros:

Imprimen en Sevilla las comedias de los ingenios menos conocidos en nombre de los que han escrito más; si es buena la comedia, usurpando a su dueño la alabanza, y si es mala, quitando la opinión al que no la ha escrito. Habrá quince días que pasé por las gradas de la Trinidad y, entre otras comedias que vendían en ellas, era el título de una Los desatinos de amor, de don Francisco de Rojas. ¿No me bastan -dije- mis desatinos, sino que con mi nombre bauticen los ajenos?

Estas falsas atribuciones partieron en particular de los libreros e impresores sevillanos (entre los que pueden señalarse los nombres de Francisco de Lyra o Manuel Faxardo) que habían comenzado por aprovecharse del tirón de Lope de Vega en las librerías. Sin embargo, muy pronto, a raíz de su muerte en 1635, van a ser otros dramaturgos los elegidos y beneficiados de las atribuciones falsas, y entre ellos estará Rojas. Lope desaparece de los encabezamientos de las comedias ajenas e incluso de las propias: suya es En los indicios la culpa que, con el nombre de Las cartas en la estafeta, se publicó a nombre de Rojas Zorrilla hacia $1635 .{ }^{14}$

Dadas estas circunstancias, se debe recelar de las atribuciones que tienen como último apoyo el nombre de Rojas en las portadas de sueltas sevillanas de la primera mitad del siglo XVII. Como ha apuntado Germán Vega, hubo un momento en que el poeta toledano fue preferido como gancho comercial para la

13 Datos recogidos de J. M. Hill, «Índice general alfabético de todas las comedias que se han escrito por varios autores, antiguos y modernos... Se hallarán en casa de los Herederos de Francisco Medel del Castillo», Revue Hispanique, 75, 1929, pp.144-369; E. Cotarelo y Mori, Don Francisco de Rojas Zorrilla, noticias biográficas y bibliográficas, Madrid, Imp. de la Revista de Archivos, 1911; y R. R. MacCurdy, Rojas Zorrilla: Bibliografía crítica, Madrid, Consejo Superior de Investigaciones Científicas (Cuadernos Bibliográficos, XVIII), 1965.

${ }^{14}$ En los indicios la culpa de Lope de Vega fue publicada en la Parte veinte y dos de las comedias del Fénix de España Lope de Vega Carpio, Zaragoza, 1630, ff. 217v-239r. La suelta sin pie de imprenta titulada Las cartas en la estafeta, a nombre de Francisco de Rojas, se conserva en la BNE, sig. T55340-20. Vid. G. Vega García-Luengos, «Treinta comedias desconocidas de Ruiz de Alarcón, Mira de Amescua, Vélez de Guevara, Rojas Zorrilla y otros de los mejores ingenios de España», Criticón, LXII (1994), pp. 57-78. 
venta por encima del mismísimo Lope y a la altura de Calderón. ${ }^{15}$ El número de obras que corrieron impresas a su nombre y que, con toda seguridad, no salieron de su pluma es significativo.

El repertorio de Rojas Zorrilla que hoy controlamos consta de 44 comedias cuya autoría en exclusiva cuenta con un margen aceptable de seguridad. Las comedias que se le atribuyen erróneamente o con garantías insuficientes, o que no aparecen, suman 43, casi tantas como las de autoría exclusiva. De éstas hay 21, que nos han llegado impresas a su nombre, que con toda seguridad no salieron de su pluma: cuatro pertenecen a Lope de Vega (Las cartas en la estafeta, El desdén vengado, La difunta pleiteada y La esclava de su galán), tres a Mira de Amescua (Los carboneros de Francia y reina Sevilla, No hay dicha ni desdicha hasta la muerte y El conde Alarcos), dos a Luis Vélez de Guevara (Don Pedro Miago y Más pesa el rey que la sangre) y una se la otorgamos a Tirso de Molina (En Madrid y en una casa), a Pedro Rosete Niño (Esto es hecho), a Alonso del Castillo Solórzano (Los encantos de Bretaña), a Andrés de Claramonte (El valiente negro en Flandes), a Melchor Fernández de León (El sordo y el montañés), a Diego de Rosas Argomedo (Donde hay valor hay honor), a Diego de Villegas (La loca del cielo) y a Salas Barbadillo (Varios prodigios de amor). Como se ha apuntado ya, tampoco es suya Los desatinos de amor ni tampoco parece serlo Don Gil de la Mancha, aunque en estos dos casos los autores no han podido ser identificados. Además, se apunta actualmente a la paternidad de Lope para Don Diego de noche ${ }^{16}$ y de Mira de Amescua para Vida y muerte del falso profeta Mahoma. ${ }^{17}$

A todos estos datos hay que añadir que de otras siete comedias que se le atribuyen en índices y documentos varios, no nos han llegado los textos: La boba para los otros y discreta para sí (que debe ser la de Lope), Buena sangre es lo mejor, Murmuraciones de la aldea, Nadie haga bien a traidores, El tercero de su afrenta (que podría ser una copia de la de Antonio Martínez de Meneses) y Vida y rapto de Elías (que podría pertenecer a Matías de los Reyes).

15 Sobre este tema, vid. G. Vega García-Luengos, «Cómo Calderón desplazó a Lope de los aposentos: un episodio temprano de ediciones espurias», en I. Arellano y G. Vega, eds., Calderón: innovación y legado. Actas del IX Congreso de la AITENSO. En colaboración con el GRISO de la Universidad de Navarra. Pamplona, 27 al 29 de marzo de 2000, New York, Peter Lang (Serie Ibérica, vol. 36), 2001, pp. 367-84.

16 Así lo cree y lo justifica V. Azcune, Dos comedias atribuidas a Lope de Vega (estudio y edición crítica), Tesis doctoral inédita, Madrid, Universidad Complutense, 2005.

17 No la citan Fajardo ni Medel y el único testimonio conservado aparece impreso a nombre Rojas en la Parte 33 de comedias de diferentes autores, Valencia, Claudio Macé, 1642. Quizá la existencia de El profeta falso Mahoma de Rojas haya hecho que también se imprima esta obra a su nombre. Agustín de la Granja aporta documentos para dar su autoría a Mira de Amescua: vid. A. de la Granja, «Comedias del Siglo de Oro censuradas por la Inquisición (Con noticia de un texto mal atribuido a Rojas Zorrilla)», en el Homenaje a Marc Vitse, en prensa. 
Algo parecido ocurre con los autos sacramentales. Se imprimen a su nombre dos autos que, con toda seguridad, no le pertenecen: El caballero del Febo, que en realidad es obra de Juan Pérez de Montalbán, y Los árboles, que no es otro que La humildad coronada de Calderón.

\section{ROJAS EN LAS COLECCIONES DE PIEZAS DE DIVERSOS AUTORES}

La trayectoria editorial de Rojas es la crónica de un éxito fulgurante. Como hemos visto, desde muy joven triunfa en los teatros de la corte madrileña y eso hace que impresores y libreros estén deseosos de imprimir obras a su nombre, suyas o no. Su popularidad es un hecho desde los inicios de la década de los treinta. Por ello va a aparecer bien representado en las grandes colecciones de la época. Incluso antes de publicar su primera parte de comedias en 1640 ya habían aparecido impresas algunas obras suyas, tanto en impresos sueltos como incluidas en partes de diversos autores. No obstante, ya advertía Pfandl de las deficiencias y de la falta de rigor de este tipo de impresos:

Las Sueltas y Colecciones son, con raras excepciones, el fruto de especulaciones mercantiles de los libreros, y así sucede que en lo referente a la pureza del texto (y en las sueltas a su integridad), lo mismo que a la autenticidad de los autores a quienes se atribuyen, no ofrecen la menor seguridad para la investigación, pues en muchos casos aparece el texto truncado, falsificado o de mérito discutible,...18

\subsection{La colección de Diferentes autores}

En esta colección, bien estudiada por Profeti, ${ }^{19}$ tiene Rojas una presencia bastante importante: trece obras suyas se incluyen en ella. Ya en la Parte 29 y en la Parte 30, ambas de 1636, aparecen obras suyas. Destaca, en especial, la repetición de la obra Casarse por vengarse: en la Parte 29 se imprime a nombre de Calderón y la Parte 30 se la adscribe a Rojas, su verdadero autor. Otras dos obras suyas merecieron el honor de ser publicadas en dos partes diferentes: Persiles $y$ Sigismunda en la 29 y en la 30, y El más impropio verdugo por la más justa venganza en la 41 y la 44 . De los tomos conservados encontramos obras de Rojas en los siguientes:

18 L. Pfandl, Introducción al estudio del Siglo de Oro, Barcelona, Casa Editorial Araluce, 1929, p. 199.

${ }^{19}$ M. G. Profeti, La Collezione «Diferentes Autores», Kassel, Edition Reichenberger, 1988. 
En Parte 29 de diferentes Autores. Valencia. Silvestre Esparsa-Juan Sonzoni. 1636: Casarse por vengarse, a nombre de Calderón, y Persiles y Sigismunda.

En Parte 30 de Comedias famosas de varios autores. Zaragoza. Hospital Real y General de Nuestra Señora de Gracia. 1636:20 Casarse por vengarse, Persiles y Sigismunda y El catalán Serrallonga.

En Parte 31 de comedias de diferentes autores. Barcelona. Jaime Romeu, a costa de Juan Sapera. 1638: Santa Isabel, reina de Portugal.

En Parte 32 de diferentes autores. Zaragoza. Diego Dormer, a costa de J. Ginobart. 1640: Obligados y ofendidos.

En Parte 41 de comedias de diferentes autores. Zaragoza. Hospital Real y General de Nuestra Señora de Gracia, a costa de Pedro Escuer. 1646: Los bandos de Verona, Sin honra no hay amistad y El más impropio verdugo por la más justa venganza.

En Parte 42 de comedias de diferentes autores. Zaragoza, Juan de Ibar-Pedro Escuer, 1650: Del rey abajo ninguno, a nombre de Calderón de la Barca.

En Parte 43 de comedias de diferentes autores. Zaragoza. Juan de Ibar, a costa de Pedro Escuer. 1650: La más hidalga hermosura.

En Parte 44 de comedias de diferentes autores. Zaragoza. Herederos de Pedro Lanaja y Lamarca. 1652: El más impropio verdugo por la más justa venganza.

En Parte 57 de Doce comedias nuevas de diferentes autores. Valencia. Juan Sonsoni. 1646: Entre bobos anda el juego y Los trabajos de Tobías.

\subsection{Doce comedias las más grandiosas... (Lisboa) ${ }^{21}$}

Esta colección consta de una serie de volúmenes publicados en Lisboa entre 1646 y 1655. En dos de ellos aparecen obras de Rojas:

En Doce comedias las más grandiosas que hasta ahora han salido de los mejores y más insignes poetas. Parte $1^{a}$. Lisboa. Lorenzo de Amberes-Juan Leyte Perera. 1646, se incluyen siete obras suyas: Casarse por vengarse, No hay amigo para amigo, No hay ser padre siendo rey, Peligrar en los remedios, Progne y Filomena, Obligados y ofendidos y El catalán Serrallonga.

En Doce comedias las más grandiosas que hasta ahora han salido de los mejores y más insignes poetas. Parte $5^{a}$. Lisboa. Pablo Craesbeeck-Felipe George. 1653, otras dos: El Caín de Cataluña y El pleito que puso el diablo con el cura de Madrilejos.

20 Y en las sucesivas ediciones: Zaragoza, Hospital Real y General de Nuestra Señora de Gracia, 1638; Sevilla, Andrés Grande, 1638; y Zaragoza, Hospital Real y General de Nuestra Señora de Gracia, 1639.

21 M. G. Profeti, «Doce comedias las más grandiosas...: una collezione teatrale lusitana del secolo XVII», La Bibliofilia. Rivista di Storia del libro e di bibliografia (Firenze), LXXX (1978), pp. 73-83. 


\subsection{La colección de Nuevas Escogidas ${ }^{22}$}

Bien representado se encuentra Rojas Zorrilla en esta colección de comedias que tanta difusión tuvo en el siglo XVII. Sin embargo, la cuestión de las autorías en esta serie es muy incierta. De las 16 comedias que aparecen impresas a nombre de Rojas, solo nueve de ellas proceden con seguridad de la pluma de Rojas. Hay otras tres impresas a nombre del toledano que son de Lope (El desdén vengado, La difunta pleiteada, Don Diego de noche), una de Vélez de Guevara (Don Pedro Miago), una de Tirso (En Madrid y en una casa), una de Salas Barbadillo (Varios prodigios de amor) y otra más cuya autoría es dudosa ( $\mathrm{La}$ prudencia en el castigo). Además, hay otras tres comedias escritas en colaboración con otros autores en las que consta su nombre y otras dos, que aparecen a nombre de tres ingenios, pero en las que es segura su participación (El monstruo de la fortuna y También tiene el sol menguante). Más problemas presentan El pleito del demonio con la Virgen y El rey Enrique el enfermo, que se imprimen a nombre de tres y seis ingenios respectivamente, y que pueden estar relacionadas también con Rojas. ${ }^{23}$ Finalmente, hay también alguna comedia que hoy incluimos en su repertorio que se publica en esta colección a nombre de otros autores: El robo de las sabinas, a nombre de Juan Coello y Arias, La trompeta del juicio a nombre de Gabriel del Corral, y La mudanza del amor, a nombre de Montalbán (es la misma que La esmeralda del amor, tradicionalmente atribuida a Rojas). Veamos, pues, la lista de comedias relacionadas con Rojas en esta colección:

Primera parte de comedias escogidas... Madrid. Domingo García y Morrás, a costa de Juan de San Vicente. 1652: La Baltasara.

Parte 5 de comedias escogidas... Madrid. Pablo de Val, a costa de Juan de San Vicente. 1653: Donde hay agravios no hay celos.

Sexta parte de comedias escogidas de los mejores ingenios de España. Zaragoza. Herederos de Pedro Lanaja y Lamarca. 1653: Los encantos de Medea.

Sexta parte de comedias escogidas..., Zaragoza. Herederos de Pedro Lanaja, a costa de Roberto Dupont. 1654: Progne y Filomena, No hay ser padre siendo rey, Obligados y ofendidos y El pleito del demonio con la Virgen.

22 Vid. E. Cotarelo y Mori, «Catálogo descriptivo de la gran colección de comedias escogidas que consta de cuarenta y ocho volúmenes, impresos de 1652 a 1704», Boletín de la Real Academia Española, XVIII (1931), pp. 232-280, pp. 418-468, pp. 583-636, pp. 772-826; XIX (1932), pp. 161-218.

23 Vid. R. González Cañal, «El rey Enrique el enfermo en el teatro español del Siglo de Oro», en C. Mata y M. Zugasti (eds.), Actas del Congreso «El Siglo de Oro en el nuevo milenio», Pamplona, EUNSA, 2005, I, pp. 829-841. 
Parte 7 de comedias escogidas... Madrid. Domingo García y Morrás, a costa de Domingo de Palacio. 1654: Don Diego de noche.

Parte 9 de comedias escogidas... Madrid. Gregorio Rodríguez, a costa de Mateo de la Bastida. 1657: El mejor amigo el muerto y El rey Enrique el enfermo

Parte 11 de comedias nuevas escogidas... Madrid. Gregorio Rodríguez, a costa de Juan de S. Vicente. 1658: El robo de las sabinas.

Parte 16 de comedias escogidas... Madrid. Melchor Sánchez-Mateo de la Bastida. 1662: El desdén vengado.

Parte 20 de comedias varias nunca impresas, compuestas por los mejores ingenios de España. Madrid. Imprenta Real. 1663: La difunta pleiteada y Don Pedro Miago.

Parte 24 de comedias nuevas y escogidas de los mejores ingenios de España. Madrid. Mateo Fernández de Espinosa Arteaga-Juan de San Vicente. 1666: El monstruo de la fortuna y También tiene el sol menguante.

Parte 31 de las comedias nuevas, escritas por los mejores ingenios de España. Madrid. José Fernández de Buendía, a costa de Manuel Meléndez. 1669: La trompeta del juicio. A nombre de Gabriel del Corral.

Parte 32 de comedias nuevas, nunca impresas, escogidas de los mejores ingenios de España. Madrid. Andrés García de la Iglesia, a costa de Francisco Serrano de Figueroa. 1669: La vida en el ataúd, El bandolero Solposto y Selva de amor y celos.

Parte 35 de comedias nuevas, escritas por los mejores ingenios de España. Madrid. Lucas Antonio de Bedmar, a costa de Antonio de la Fuente. 1670: En Madrid y en una casa y La hermosura y la desdicha.

Parte 42 de comedias nuevas, nunca impresas, escogidas de los mejores ingenios de España. Madrid. Roque Rico de Miranda, a costa de Juan Martín Merinero. 1676: Varios prodigios de amor.

Parte 44 de comedias nuevas, nunca impresas, escogidas de los mejores ingenios de España. Madrid. Roque Rico de la Miranda, a costa de Juan Martín Merinero. 1678: La prudencia en el castigo.

Parte 45 de comedias nuevas, escogidas de los mejores ingenios de España. Madrid. J. Fernández de Buendía-J. Fernández. 1679: Los bandos de Verona y La mundanza en el amor, a nombre de Montalbán. ${ }^{24}$

\subsection{Volúmenes varios}

Otros volúmenes en los que aparecen obras de Rojas en la segunda mitad del XVII y principios del XVIII son los siguientes:

24 M. G. Profeti, Per una bibliografia di Juan Pérez de Montalbán, Verona, Univ. degli Studi di Padova, 1976, pp. 175-177. 
El mejor de los mejores libros que ha salido de comedias nuevas. Alcalá. María Fernández-Tomás Alfay. 1651: El Caín de Cataluña.

Flor de las mejores doce comedias de los mayores ingenios de España. Madrid. Diego Díaz de la Carrera. 1652: El pleito que tuvo el diablo con el cura de Madrilejos.

El mejor de los mejores libros que han salido de comedias nuevas. Madrid. María de Quiñones-Manuel López. 1653: El Caín de Cataluña.

Autos sacramentales con cuatro comedias nuevas, y sus loas y entremeses. Primera parte. Madrid. María de Quiñones. 1655: Los obreros del Señor, El gran patio de Palacio y Galán, discreto y valiente.

Navidad y Corpus Christi, festejados por los mejores ingenios de España. Madrid. José Fernández Buendía, a costa de Isidoro de Robles. 1664: El Caballero del Febo.

Autos sacramentales, y al nacimiento de Cristo, con sus loas y entremeses, recogidos de los mayores ingenios de España. Madrid. Antonio Francisco de Zafra. 1675: Galán, discreto y valiente, El gran patio de Palacio (a nombre de Moreto) y Los obreros del Señor.

Doce comedias las más famosas... de los mejores ingenios de España. Primera parte. Colonia. Manuel Texera. 1697: No hay ser padre siendo rey y También la afrenta es veneno.

Comedias escogidas de diferentes libros, de los más célebres e insignes poetas. Bruselas. Manuel Texera Tartaz. 1704: Casarse por vengarse y El más impropio verdugo, por la más justa venganza.

Posteriormente, en 1785, Vicente García de la Huerta incluirá Entre bobos anda el juego y Donde hay agravios no hay celos en su Theatro Español, Madrid, Imprenta Real, 1785, Parte primera, tomo I y Parte segunda, tomo I, respectivamente.

\section{ROJAS EN SUELTAS}

La difusión de Rojas en impresos sueltos fue muy abundante. Ya hemos visto cómo el propio autor, como también hicieran Lope o Calderón, se quejaba amargamente de que le atribuían obras que no eran suyas. Parece que desde muy pronto su nombre gozó de fama y popularidad y eso hizo que se le adscribieran en la imprenta bastantes obras ajenas a su pluma. Además, algunas de sus comedias más conocidas tuvieron larga vida en las prensas de los siglos XVII y XVIII.

Gracias a la catalogación exhaustiva de los testimonios de las obras de Rojas que hemos llevado a cabo, ${ }^{25}$ podemos hacer hoy el recuento aproximado

${ }^{25}$ Vid. R. González Cañal, U. Cerezo Rubio y G. Vega García-Luengos, Bibliografía de Francisco de Rojas Zorrilla, Kassel, Reichenberger, 2006. 
de las sueltas de este autor. Evidentemente, muchas se han debido perder, y es posible que sólo se hayan conservado un tercio de las que realmente se llegaron a imprimir. En total, hemos catalogado más de dos centenares de diferentes ediciones sueltas de obras impresas a nombre de Rojas. Las cifras son significativas, ya que nos dan pistas sobre los títulos que más difusión tuvieron, al menos entre el público lector, en el período de vigencia de este tipo de impresos. Los resultados no dejan de sorprender:

Los áspides de Cleopatra: 22 sueltas

El catalán Serrallonga: 22

Donde hay agravios no hay celos: 19

El mejor amigo el muerto: 17

Casarse por vengarse: 16

El desafío de Carlos V: 15

Progne y Filomena: 15

No hay ser padre siendo rey: 15

Del rey abajo ninguno: 14

El monstruo de la fortuna: 14

El más impropio verdugo: 13

Los encantos de Medea: 11

No hay amigo para amigo: 10 .

El Caín de Cataluña: 9

La más hidalga hermosura: 9

También la afrenta es veneno: 7

Primero es la honra que el gusto: 7

El falso profeta Mahoma: 6

El pleito que tuvo el diablo con el cura de Madrilejos: 6

La esmeralda del amor: 6

Los bandos de Verona: 6

Abre el ojo: 5

El pleito del demonio con la virgen: 5

Entre bobos anda el juego: 4

Peligrar en los remedios: 4

Los trabajos de Tobias: 4

Lo que son mujeres: 2

El robo de las sabinas: 2

Es curioso comprobar cómo las obras por las que hoy se conoce fundamentalmente al poeta toledano no se encuentran en una posición destacada: Del rey abajo ninguno, con 14 sueltas, y Entre bobos anda el juego, que 
cuenta con solo cuatro sueltas. La fama de estas obras parece ser más tardía. Tampoco la vida editorial de Abrir el ojo es demasiado boyante, a pesar del positivo aprecio que tuvieron a la obra los preceptistas neoclásicos. ${ }^{26}$

En cambio, encabezan la lista obras que tuvieron un éxito incuestionable en los escenarios dieciochescos, según demuestran los datos recogidos por Andioc y Coulon sobre los teatros de Madrid: Los áspides de Cleopatra, El catalán Serrallonga y Donde hay agravios no hay celos. ${ }^{27}$

Además, hemos localizado también cinco relaciones de Los áspides de Cleopatra, cuatro de No hay amigo para amigo, tres de El catalán Serrallonga y una de No hay ser padre siendo rey.28 Este tipo de impresos surgieron en el último tramo del siglo XVII y alcanzaron gran auge en el primer tercio del siglo siguiente, sobre todo en Andalucía y, en particular en Sevilla. ${ }^{29}$ Evidentemente las relaciones se extraían de obras que habían alcanzado cierto grado de popularidad.

Las cifras de las sueltas de Rojas son significativas. Lejos están, desde luego, de las más de 40 sueltas de los siglos XVII y XVIII que se recogen de La vida es sueño. ${ }^{30}$ No obstante, estos datos demuestran que tras Calderón y Moreto es uno de los dramaturgos de más éxito en las librerías de los siglos XVII y XVIII.

\section{ROJAS EN LA IMPRENTA MODERNA}

Una vez que comienza a funcionar lo que se ha dado en llamar imprenta moderna, es decir, en torno a 1830, Rojas va a ir perdiendo terreno poco a poco. Es verdad que entre 1827 y 1831 se publicaba en Madrid dos tomos de comedias

\footnotetext{
26 Vid. F. B. Pedraza Jiménez, «Abrir el ojo de Rojas Zorrilla bajo el antiguo régimen», Criticón, 8788-89, 2003, pp. 637-648 y «De Rojas Zorrilla a Enciso Castrillón: Abrir el ojo en la escena decimonónica», en A zaga de tu huella. Homenaje al prof. Cristóbal Cuevas, Málaga, Universidad de Málaga, 2005, I, pp. 539-557.

27 Sobre esta última obra, vid. F. B. Pedraza Jiménez, «Donde hay agravios no hay celos: un éxito olvidado», en Actas de las XIX Jornadas de teatro del Siglo de Oro, Almería, 4-19 de abril de 2002, en prensa.

28 A las ya recogidas en la Bibliografía de Francisco de Rojas Zorrilla antes citada (núms. 45-49, 155157 y 552-553), hay que añadir ahora dos más de No hay amigo para amigo (Madrid, BNE, V.E. 43-50 y V.E. 385-50) y una de No hay ser padre siendo rey (Madrid, BNE, V.E. 385-38), localizadas recientemente.

29 Vid. J. Moll, «Un tomo facticio de pliegos sueltos y el origen de las relaciones de comedias», Segismundo, 23-24, 1976, pp.143-167.

30 Vid. G. Vega García-Luengos, D. W. Cruickshank y J. M. Ruano, La segunda versión de «La vida es sueño» de Calderón, Liverpool, University Press, 2000.
} 
de Rojas a cargo de la Imprenta de Ortega. ${ }^{31}$ Incluye un total de ocho comedias: Del rey abajo ninguno, Donde hay agravios no hay celos, Entre bobos anda el juego, Don Diego de noche, Lo que son mujeres, Abre el ojo, El desdén vengado y Progne y Filomena. Persiste aún en esta edición un clamoroso error de autoría: se atribuye a Rojas El desdén vengado, cuya paternidad es sin lugar a dudas de Lope de Vega; también incluye Don Diego de noche, que probablemente sea asimismo obra del Fénix. Entre las obras seleccionadas están presentes las cinco obras de Rojas de mayor difusión en los dos últimos siglos: Del rey abajo ninguno, Donde hay agravios no hay celos, Entre bobos anda el juego, Los que son mujeres y Abre el ojo.

En 1838 sale a la luz el Tesoro del teatro español desde su origen (1356) hasta nuestros días, editado por Eugenio de Ochoa, París, Librería Europea de Baudry, 1838. En el tomo IV incluye tres obras de Rojas: Del rey abajo ninguno, Donde hay agravios no hay celos y Entre bobos anda el juego. Los elogios que hace en el prólogo a la primera de ellas denotan claramente la difusión y consideración que empezaba a alcanzar esta obra:

Es tan popular esta comedia en España, que apenas hay joven medianamente educado que no recite de memoria algunos trozos de ella; en los teatros de las ciudades se representa continuamente, y aun en los lugares y aldeas es muy conocida por ser la primera que sacan á relucir, cuando pasan por ellas, las trashumantes compañías de cómicos de la legua. Puede decirse, pues, que esta comedia es la más generalmente conocida en España de todas las de nuestro inmenso repertorio. ${ }^{32}$

En 1861 se imprime el volumen 54 de la Biblioteca de Autores Españoles, a cargo de Ramón de Mesonero Romanos en el que publica un total de 30 obras del poeta toledano. Se trata de la edición más completa del teatro de Rojas hasta la fecha, aunque no está exenta de errores. En la Biblioteca Histórica Municipal de Madrid se conservan unos apuntes manuscritos de Mesonero Romanos que corresponden a la confección del volumen: ${ }^{33}$ son siete hojas en donde copia distintas listas de títulos que barajó a la hora de seleccionar las obras que iba a publicar en el volumen. Desde el punto de vista de la autoría, la edición de Mesonero todavía siembra dudas y contiene errores: incluye, por ejemplo, entre

\footnotetext{
31 Comedias escogidas de don Francisco de Rojas Zorrilla, Madrid, Ortega y Compañía, 1827-1831, 2 vol.

32 En Tesoro del teatro español desde su origen (1356) hasta nuestros días, ed. de Eugenio de Ochoa, Madrid, Librería Europea de Baudry, 1838, IV, p. 339. Dos años después se publica una selección de esta obra titulada Colección de piezas escogidas... sacadas del Tesoro del teatro español, formado por Eugenio Ochoa, París, Baudry, Librería Europea, que incluye las dos primeras obras de Rojas citadas anteriormente. El Tesoro... de Ochoa se reeditó después en París, Garnier Hermanos, 1898.

${ }^{33}$ Madrid, Biblioteca Histórica Municipal (BHM), sig. FMR 14,1.
} 
las obras editadas a nombre de Rojas la titulada Don Pedro Miago, obra que en la actualidad se adjudica sin lugar a dudas a Vélez de Guevara. Tampoco Don Diego de noche, como hemos visto, se considera en la actualidad obra de Rojas. Es en esta edición en la que las sucesivas generaciones de estudiosos y aficionados al teatro han leído al autor toledano. El volumen ha sido reimpreso en los años 1866, 1897, 1908, 1918, 1926 y 1952.

Francisco José Orellana publica poco después el Tesoro selecto antiguo y moderno, nacional y extranjero, coleccionado e ilustrado con una introducción, notas, observaciones críticas y biografías de los principales autores... Barcelona, Salvador Manero, 1867. En el tomo II de esta colección se editan ocho obras de nuestro autor: Del rey abajo ninguno, Don Diego de noche, Donde hay agravios no hay celos, Obligados y ofendidos, Entre bobos anda el juego, La traición busca el castigo, Lo que son mujeres y Abre el ojo. Insiste de nuevo en los títulos que anteriormente había seleccionado la imprenta de Ortega añadiendo dos nuevos títulos: Obligados y ofendidos y La traición busca el castigo.

Años más tarde aparecía otro volumen con cuatro comedias de Rojas: Comedias escogidas de Francisco de Rojas Zorrilla..., Barcelona, Daniel Cortezo y Compañía, 1884 (Biblioteca Clásica Española): Del rey abajo ninguno, Entre bobos anda el juego, Lo que son mujeres y Donde hay agravios no hay celos. Estas cuatro obras parecen conformar el canon rojiano desde finales del siglo XIX.

Sin embargo, se puede constatar que Rojas pierde notoriedad y presencia en las imprentas a medida que avanza el siglo XX. Excepto alguna edición ocasional, ${ }^{34}$ solo dos obras tienen una difusión impresa significativa a lo largo de dicha centuria: tenemos registradas 32 ediciones de Del rey abajo ninguno y 18 de Entre bobos anda el juego. Aparte de estas dos obras, cabe destacar el éxito que tuvo Lo que son mujeres en las imprentas de la primera mitad del siglo XX. Quizá fuera a causa de su llamativo título, pero el caso es que contamos al menos con cinco ediciones: en Barcelona, Juan Molins, 1907; en Barcelona, Casa Editorial Europa, 1924; en Teatro clásico. Colección de las mejores obras teatrales escritas por los clásicos españoles, Barcelona, Colección «Algo», 1929; en F. de Rojas Zorrilla, Comedias, Valencia, Prometeo, s.a.; en F. de Rojas Zorrilla, Comedias, ed. José Mallorquí Figuerola, Barcelona, El Molino, 1942 (editada junto a Del rey abajo, ninguno y Entre bobos anda el juego).

En las últimas décadas, salvo algunas ediciones ocasionales, son Entre bobos anda el juego y Del rey abajo ninguno las obras que se repiten en las colecciones de clásicos, como ya hemos señalado. Precisamente, esta última comedia, que los editores y críticos asocian sistemáticamente a su nombre, tiene

34 Por ejemplo la edición de Cada cual lo que le toca y La viña de Nabot, a cargo de Américo Castro, Madrid, Sucesores de Hernando, 1917. 
todavía serios problemas de autoría: es muy probable que, a pesar de la insistencia en ligarla al nombre de Rojas, se trate de una atribución espuria.

\section{OTROS APECTOS SIGNIFICATIVOS}

Los datos que arroja el análisis de la trayectoria impresa del teatro de Rojas se confirman si atendemos a otros aspectos. ${ }^{35}$ Uno de ellos sería el éxito indudable de muchas de sus obras en los escenarios dieciochescos, como antes hemos apuntado, a juzgar por las cifras de las representaciones. Las noticias parciales sobre representaciones de obras de Rojas en los teatros del XIX avalan la formación de un canon rojiano que cuenta con cinco obras: Del rey abajo ninguno, Lo que son mujeres, Abre el ojo, Donde hay agravios no hay celos y Entre bobos anda el juego. ${ }^{36}$ Como dato significativo, cabe destacar que Los áspides de Cleopatra, una de las obras de Rojas más representada en el siglo anterior, desaparece prácticamente de los escenarios decimonónicos. ${ }^{37}$

Otro aspecto a tener en cuenta es el número de obras del toledano que fueron objeto de refundición. Desde que Tomás Sebastián y Latre eligiera en 1773 la pieza titulada Progne y Filomena para adaptarla y proponerla como modelo de tragedia, parece que Rojas se convierte en foco de atracción para refundidores y escritores dramáticos. Pero es en la primera mitad del siglo siguiente cuando se localizan más refundiciones. ${ }^{38}$ Las obras elegidas son seis: Abre el ojo, Del rey abajo ninguno, Donde hay agravios no hay celos, Entre bobos anda el juego, Lo que son mujeres y No hay amigo para amigo. ${ }^{39}$ En el siglo XX hay tres refundiciones más de Entre bobos anda el juego, dos de Del rey abajo ninguno y una de Donde hay agravios no hay celos, más algunas versiones más recientes de tres

\footnotetext{
35 También el número de manuscritos teatrales conservados puede darnos una idea de la difusión de su teatro: 53 manuscritos del siglo XVII, 35 del XVIII y 20 del XIX; vid. R. González Cañal, U. Cerezo Rubio y G. Vega García-Luengos, op.cit.

${ }^{36}$ Los datos que aporta Adams sobre las representaciones en Madrid entre 1820 y 1850 son los siguientes: 79, 44, 30, 21 y 4 representaciones para las obras citadas; sólo se incrusta en esta lista Los encantos de Medea que cuenta con 6 representaciones; vid. N. B. Adams, «Siglo de Oro plays in Madrid, 1820-1850», Hispanic Review, IV (1936), pp. 342-357.

${ }^{37}$ El último montaje del que tenemos noticia lo llevó a cabo la Compañía de Luis Navarro el 1 de enero de 1798; vid. E. Cotarelo y Mori, Isidoro Máiquez y el teatro de su tiempo, Madrid, Imprenta de José Perales y Martínez, 1902, p. 601.

$38 \mathrm{Vid}$. D. T. Gies, «Notas sobre Grimaldi y el "furor de refundir" en Madrid (1820-1833)», Clásicos después de los clásicos, Cuadernos de Teatro Clásico, 5 (1990), pp. 111-124.

39 Dos de ellas a cargo de Félix Enciso Castrillón (Abre el ojo y Entre bobos anda el juego), y las otras de Dionisio Solís (Del rey abajo ninguno), el mexicano Manuel Eduardo Gorostiza (Lo que son mujeres), Hartzenbusch (Donde hay agravios no hay celos) y Antonio Marín (No hay amigo para amigo); vid. R. González Cañal, U. Cerezo Rubio y G. Vega García-Luengos, op.cit.. núms. 12-13, 237, $318,443-446$ y 555.
} 
obras que han sido llevadas a escena: la de José Manuel Caballero Bonald de Abre el ojo en 1979, la de Rafael Pérez Sierra y Gerardo Malla del Entre bobos anda el juego, que montó la Compañía Nacional de Teatro Clásico veinte años después, y la de Fernando Doménech de Obligados y ofendidos, publicada en el año 2000.40

También el número de traducciones y adaptaciones a otras lenguas están en la misma línea de los datos que venimos presentando. Dejando de lado la estela de Rojas en Francia e Inglaterra en la segunda mitad del XVII y principios del XVIII, al revisar la lista de obras que han sido traducidas a otras lenguas de nuevo los títulos son los esperables: Del rey abajo ninguno, Donde hay agravios no hay celos y Entre bobos anda el juego. ${ }^{41}$ Como casos curiosos se pueden citar la traducción al inglés de Los bandos de Verona y la traducción francesa de Lo que son mujeres, ambas realizadas en la segunda mitad del siglo XIX.42

Todos estos datos nos confirman la difusión y popularidad de algunas obras del dramaturgo toledano en los siglos XVIII y XIX. Además, a medida que avanza ese último siglo parece que se va forjando una especie de repertorio esencial de Rojas que contendría un total de cinco piezas, como hemos señalado antes. Sin embargo, en el siglo XX vemos claramente que Rojas deja de interesar muy pronto a editores e impresores. Este desinterés hace que se olviden algunas de sus obras básicas. Así, en las dos primeras décadas del siglo sólo disfrutan de cierto reconocimiento en la imprenta dos de sus obras, Del rey abajo ninguno y Entre bobos anda el juego, seguidas a bastante distancia por Lo que son mujeres.

\footnotetext{
40 Abre el ojo, versión de J. M. Caballero Bonald, Madrid, Centro de Documentación Teatral, 1979; Entre bobos anda el juego, versión de R. Pérez Sierra y G. Malla, prólogo de F. B. Pedraza, Madrid, CNTC, 1999; y Obligados y ofendidos, versión de F. Doménech, Madrid, RESAD-Editorial Fundamentos, 2000.

${ }^{41}$ Hemos registrado tres traducciones alemanas, dos francesas y una italiana en el siglo XIX de Del rey abajo ninguno, más dos inglesas en el siglo XX (vid. R. González Cañal, U. Cerezo Rubio y G. Vega García-Luengos, op.cit., núms. 229-236). De Donde hay agravios... hemos localizado dos traducciones alemanas, ambas del siglo XX (ibid., núms. 325-326). Finalmente, contamos con dos ediciones en alemán de Entre bobos anda el juego, una del siglo XIX y otra del XX (ibid., núms. 385386). Sobre la fortuna de Rojas en Italia, véase en este mismo volumen el artículo de Elena $\mathrm{E}$. Marcello titulado «La recepción del teatro de Francisco de Rojas Zorrilla en Italia. Algunas anotaciones».

42 Los bandos de Verona fue traducida por F. W. Corens (London, 1874), mientras que Lo que son mujeres fue traducida al francés por Antoine L.-A. Fée y publicada en Études sur l'ancien théâtre espagnol, París, Firmin Didot Frères, fils et Cie., 1873 (ibid., núms. 73 y 440, respectivamente).
} 


\section{LA ACTUALIDAD EDITORIAL DE ROJAS ZORRILLA}

La suerte de Rojas parece haber cambiado en los últimos años. ${ }^{43}$ Han tenido que pasar bastantes décadas para que el trabajo de recuperación del teatro de Rojas iniciado por MacCurdy a mediados del siglo XX se haya visto continuado. En los últimos años contamos con la edición de Profeti de Entre bobos anda el juego, y con dos ediciones de obras menos frecuentes: Lo que son mujeres y Casarse por vengarse. ${ }^{44}$ En 2005 la editorial Castalia ha publicado una rigurosa edición de Donde hay agravios no hay celos y Abrir el ojo, a cargo de Felipe B. Pedraza Jiménez y Milagros Rodríguez Cáceres. En la actualidad un amplio equipo ligado al Instituto Almagro de Teatro Clásico de la Universidad de Castilla-La Mancha trabaja en la edición crítica de las obras de este dramaturgo. El primer tomo, que contiene las primeras cuatro comedias de la Primera Parte, está a punto de salir a la luz. Los siguientes tomos, siempre con cuatro comedias cada uno, se encuentran en preparación. Esperamos que poco a poco se pueda ir editando el corpus dramático de Rojas en ediciones críticas fiables y solventes. Sólo así se podrá analizar y valorar su obra para colocarla en su justo lugar.

\footnotetext{
43 Incluso en los escenarios la estrella de Rojas parece haber cambiado. Hemos citado las representaciones de 1999 de Obligados y ofendidos, a cargo de la RESAD y de Entre bobos anda el juego por parte de la Compañía Nacional de Teatro Clásico. Posteriormente, Abre el ojo también ha sido objeto de un montaje dirigido por Francisco Plaza. Para el 2007, año del centenario, se anuncia el montaje de Del rey abajo ninguno, dirigido por Laila Ripoll, por la Compañía Nacional de Teatro Clásico.

${ }^{44}$ Lo que son mujeres, en D. Castillejo, La formación del actor en el teatro clásico. Ejercicios en torno a ocho obras clave del Siglo de Oro, Madrid, Ars Millenii, 2004, II, pp. 847-1004; Casarse por vengarse, ed. L. L. Mullin, Kassel, Reichenberger, 2006.
} 